\title{
Memory of Professor Charles (Chuck) S. Fadley (1941.9-2019.8)
}

\author{
Hiroshi Daimon, ${ }^{\mathrm{a}, \dagger}$ Claus M. Schneider, ${ }^{\mathrm{b}}$ Bongjin Simon Mun ${ }^{\mathrm{c}}$ \\ ${ }^{a}$ Toyota Physical and Chemical Research Institute, 41-1, Yokomichi, Nagakute, Aichi 480-1192, Japan \\ ${ }^{\mathrm{b}}$ Peter Gruenberg Institute, Research Center Juelich, 52425 Juelich, Germany \\ ${ }^{\mathrm{c}}$ Gwangju Institute of Science and Technology, Department of Physics and Photon Science, 123 Cheomdangwagi-ro, Gwangju, Korea. \\ † Corresponding author: daimon@toyotariken.jp
}

Received: 20 January, 2020, Accepted 4 June, 2020, Published 27 June, 2020

Professor Charles S. Fadley (nicknamed Chuck), who was a global leader in photoelectron spectroscopy using synchrotron radiation, passed away on 1st August 2019 at the age of 77 . He was a well-known founder of photoelectron diffraction, and as a front runner in photoelectron spectroscopy using synchrotron radiation he initiated and promoted several novel approaches; such as, photoelectron holography, hard X-ray photoelectron spectroscopy, soft-X-ray standing wave spectroscopy, and more. He contributed to many scientific activities and served scientific communities including this ALC conference. He was an honorable member of the JSPS 141st Committee and a laureate of JSPS 141st Committee Award. This paper summarizes his life to honor his great achievements in science and contributions to scientific communities.

Keywords Charles S. Fadley; Photoelectron diffraction; Photoelectron holography; Hard X-ray photoelectron spectroscopy; X-ray standing wave spectroscopy

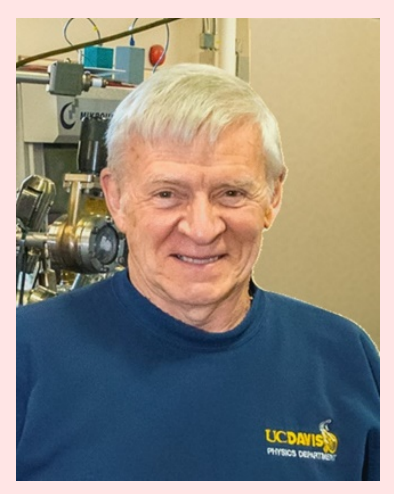

\section{LIFE OF CHUCK}

Since he loved to be called "Chuck", we use this nickname throughout this article. Chuck was born in Ohio, USA on September 4th, 1941. He showed an excellence at the local Norwalk High School, winning the National Mathematics Contest, and he graduated as a co-valedictorian. He graduated from the Department of Chemical Engineering at the Massachusetts Institute of Technology in 1963. He completed his master's program at the University of California, Berkeley in 1965 under the supervision of Prof. R. A. Wallace. The title of his Master Thesis is "Electrical Conductivity and Ionic Transport Phenomena in a Polycationic Membrane". He received his doctorate in 1970 at the same university under the supervision of Prof. D. A. Shirley. The title of his $\mathrm{Ph}$. D. Thesis is "Core and Valence Electronic States Studied with X-ray Photoelectron Spectroscopy".

After several post-doctoral positions and a visiting assistant professorship at Linkoping University in Sweden, he became an associate professor in the Department of Chemistry at the University of Hawaii starting from 1974, and was a professor from 1978 to 1991 . In the meantime, he spent his time as a visiting professor at the University of Paris (at the LURE synchrotron radiation facility) and at Utah University. In 1990, he moved to the world's first third-generation synchrotron radiation facility, the Advanced Light Source (ALS) in the Lawrence Berkeley National Laboratory (LBNL) in California, U.S.A., and became a full professor at the Department of Physics at the University of California, Davis, and also an ALS professor in LBNL. He continued to work in these positions until the end.

\section{RESEARCH IN HAWAII}

At the University of Hawaii, Chuck started angle-resolved X-ray photoelectron spectroscopy (XPS), especially photoelectron diffraction in his laboratory. Professor Shozo Kono, Professor Jürg Osterwalder, and many people contributed to the establishment of photoelectron diffraction during the initial stage. The field of photoelectron diffraction can be said to have spread to the world from there. Figure 1 shows the first beautiful photoelectron diffraction pattern from $\mathrm{O} / \mathrm{Cu}(001)$ [1] superimposed on the scenery of Hanauma bay in Hawaii.

The period from 1974 to 1990 , when Chuck stayed at the 


\section{eJSSNT}

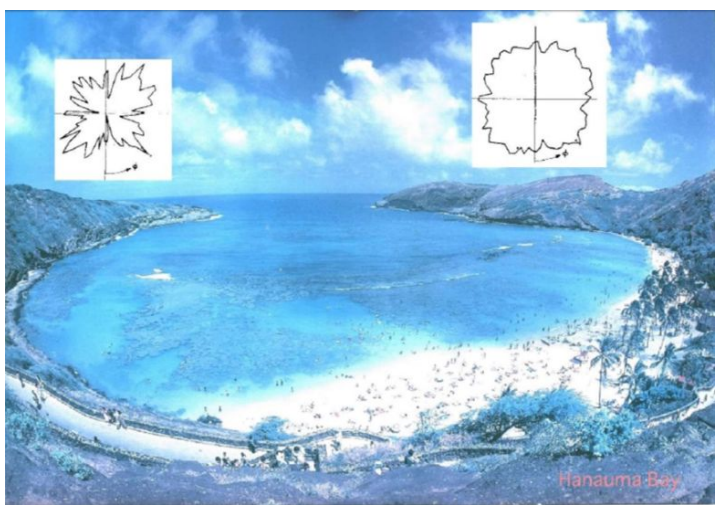

Figure 1: First beautiful photoelectron diffraction pattern from $\mathrm{O} / \mathrm{Cu}(001)$ and Hanauma Bay. Courtesy of Prof. Kono.

University of Hawaii, is the dawn of world's synchrotron radiation science. In Japan, the world's first synchrotron radiation storage ring, INS-SOR was constructed in 1975, and the Photon Factory (PF) was constructed in 1982. Chuck performed experiments of synchrotron radiation photoelectron diffraction at the Stanford synchrotron radiation facility in the late 1970s.

One of the authors (H.D.) started photoelectron diffraction using synchrotron radiation in his doctoral dissertation research (1978-83), and he paid a courtesy visit to Chuck's laboratory in Hawaii in 1982 (Figure 2).

\section{RESEARCH IN CALIFORNIA}

The year of 1990, when Chuck moved to ALS, is also the dawn of photoelectron holography, and he began to develop photoelectron holography [2]. Since then, Chuck has always been at the forefront of synchrotron radiation photoelectron spectroscopy, including researches on spin \& magnetism [3], resonant photoemission [4], standing waves [5], and hard X-ray photoelectron spectroscopy (HAXPES) [6]. Since HAXPES experiments are difficult to carry out at ALS, Chuck started regular activities at several synchrotron facilities outside the US, such as SPring-8, ESRF and later Soleil,

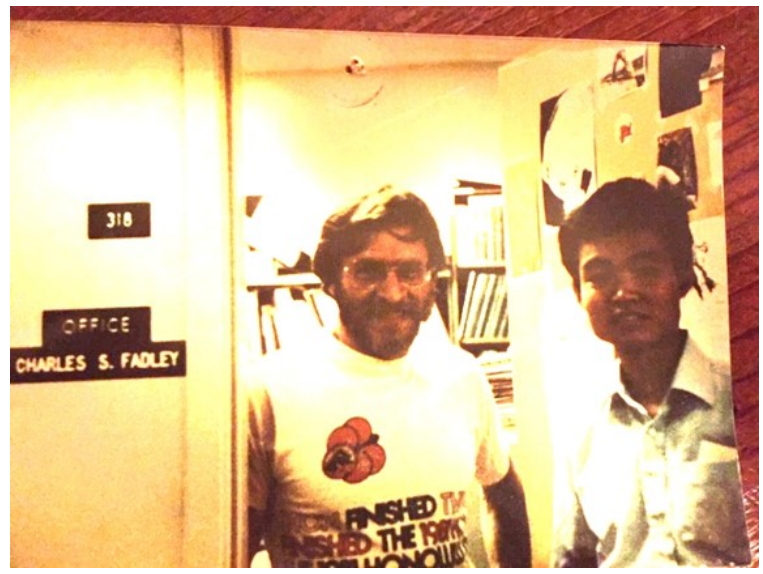

Figure 2: Chuck (left) and H.D. (right) at the University of Hawaii in 1982.
ALC '19 Conference

Diamond, and PETRA. Chuck has spread these studies around the world with 235 invited talks throughout his life and has always enlightened many researchers. The total number of his papers is 332 , and the average number of citations remains at the high level of 36 .

H.D. stayed for ten months from July 1994 to May 1995 at Chuck's laboratory in LBNL with several PhD students, postdocs and visiting researchers. The Scienta analyzer was to be introduced to the ALS beam line, but its actual use started just two weeks before H.D. returned to Japan. At that time, the long-awaited circularly-polarized-light photoelectron diffraction experiment was realized. More than 20 Japanese have stayed in Chuck's laboratory, especially H.D.'s students at Nara Institute of Science and Technology have been taken care of short-term stays almost every year.

The experimental apparatus was very big, with a Scienta analyzer rotating by large bellows, and was nicknamed Big Blue because the columns were blue. Figure 3 shows a photo of Big Blue and a happy Chuck. Chuck's wife Susan said he was like a cowboy for the whole his life, and the picture shows this in his appearance. Chuck's favorite car was a Honda red luxury sports car, Acura Integra. He liked its good acceleration with "Zoom Zoom Zoom" and enjoyed climbing the slope to his house in the Berkeley Hills and driving to Davis. Both ALS and Chuck's house were on a hillside overlooking San Francisco Bay, making them wonderful places to enjoy the sunset over the Golden Gate Bridge in the evening. Sometimes Chuck invited friends and everyone and had a home party.

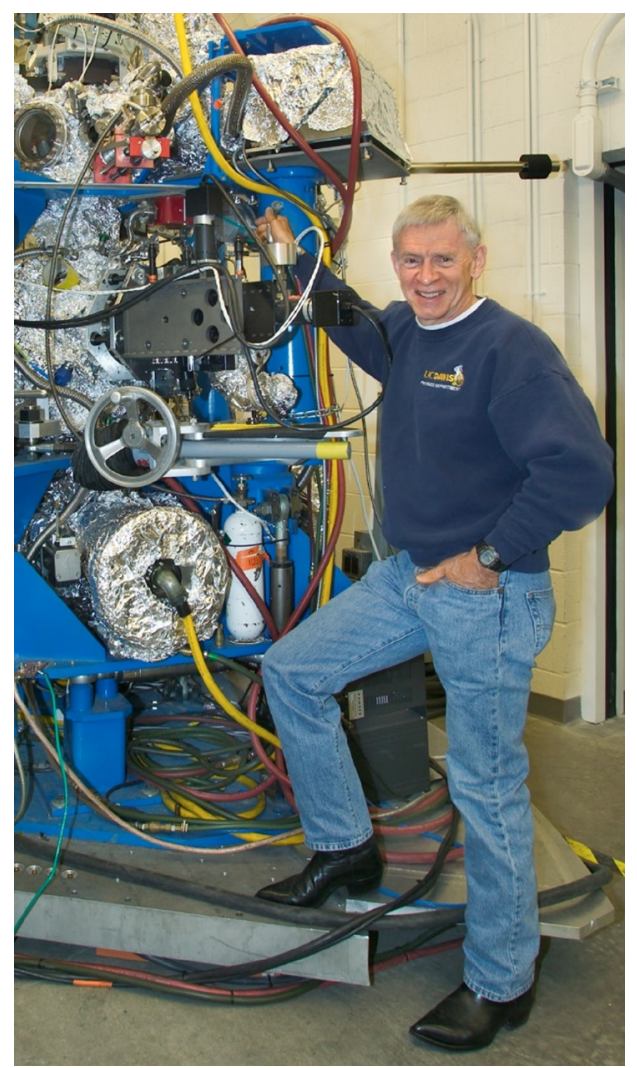

Figure 3: Big Blue and Chuck. 


\section{eJSSNT}

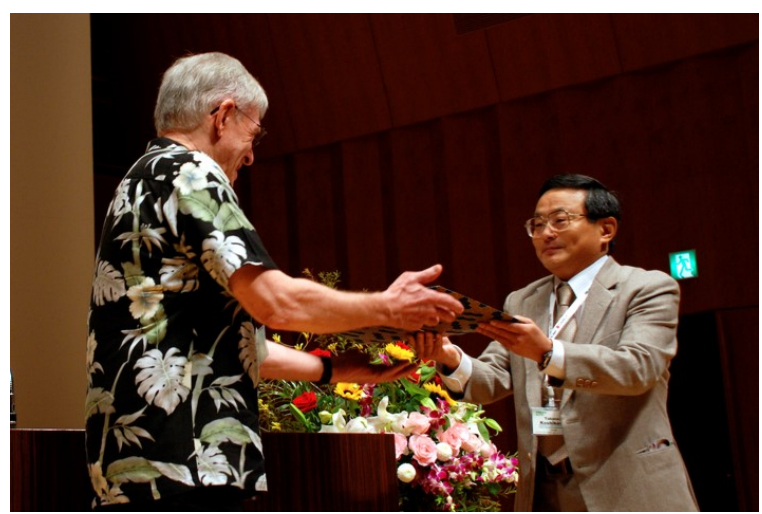

Figure 4: Chuck receiving the Award of the 141st Committee on Microbeam Analysis of the Japanese Society for the Promotion of Sciences (JSPS) from Prof. Takanori Koshikawa (Osaka Electro-Communication Univ.) at the ALC '07 meeting in Kanazawa, October 2007.

\section{CHUCK AND SCIENTIFIC COM- MUNITY}

Chuck's contribution to the scientific community was very large and impressive. He has been the center of organization of the International Conference on Electron Spectroscopy (ICES) since the beginning. At the meeting at Berkeley, Chuck took the initiative to change the name of the meeting to ICESS (International Conference on Electronic Spectroscopy and Structure) and expanded the scope, which increased the number of participants, almost doubling, to around 400 . He was the chair of the Editorial board of the Journal of Electron Spectroscopy and Related Phenomena. $\mathrm{He}$ was a regular organizing committee member of several international conferences such as VUV (later VUVX) and HAXPES. At an international conference hosted by Japan, he was an international adviser on International Symposium on Surface Science (ISSS) and International Symposium on Atomic Level Characterizations for New Materials and Devices (ALC). He is the first international fellow at The Surface Science Society of Japan (The Japan Society of Vacuum and Surface Science since 2018). He has been awarded the JSPS 141 Award and the International Honorary Member of the JSPS 141 Committee (Figure 4). Chuck received many other awards, including the AVS Welch Award and the Helmholtz-Humboldt Award. The latter brought him to Germany and enabled a close collaboration with the institute of C.M.S. at the Research Center Juelich, which lasted until the end.

\section{CHUCK IN CONFERENCES}

Chuck contributed to the science community not only as an organizer, but also as an important attendee. H.D. thanks Chuck for his help as an international advisor for the new academic research project "3D Active-Site Science" [7] that H.D. was representing, and also as an attendee to the pro-

\section{ALC '19 Conference}

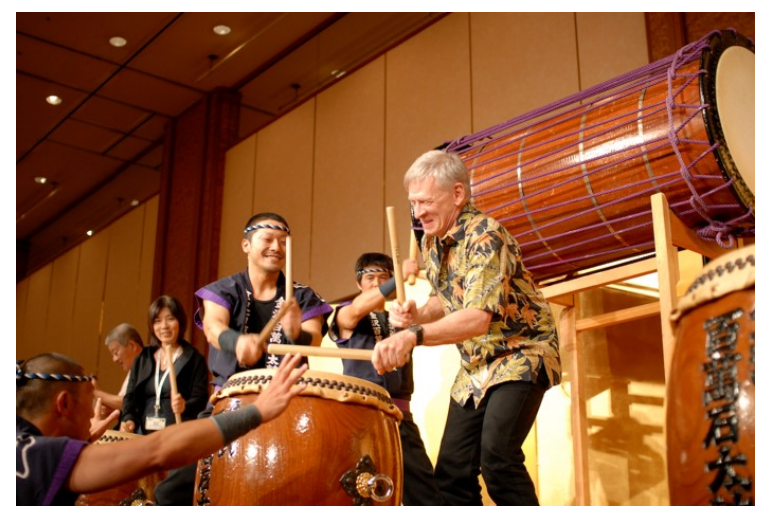

Figure 5: Chuck drumming a Japanese big drum at the banquet of the ALC '07 meeting in Kanazawa, October 2007.

ject's conference (VUVX satellite meeting) held at the University of Zurich in July 2016. ALC was often held in Hawaii, and Chuck gave invited talks every time from the 2003 meeting. He was an important performer at the banquet as shown in Figure 5 to excite the meeting. At the ALC banquet held in Kauai, Hawaii in 2017, he showed some interesting snapshots of the meeting. Chuck made everyone laugh with the Band-Aid covering the wound on H.D.'s mouth which looked like a false mustache. At that time, he did not show anything about his illness, but if we now think, he should have already been in a serious fight with illness.

\section{CHUCK'S 75-YEAR-OLD BIRTH- DAY PARTY}

In September 2016, his 75-year-old birthday party was held in Berkeley, where his acquaintances from around the world gathered to celebrate him as shown in Figure 6. We were wondering why it was a half-hearted year of 75 instead of 80 , but we knew it was the last chance to hold it. We are glad that everyone could celebrate him. Chuck also said it was the happiest day for him. After June 2018 Chuck could no longer travel and had to cancel his scheduled invited talks or ask for substitutes. In September 2018, he was invited to TASPEC (Trends in Advanced Spectroscopy in Materials Science) conference in Japan, but he could not come, and everyone was worried about what had happened to him. Those who visited him in Berkeley during this final period, always found him in a very positive attitude to life, although his illness was leaving its marks on him. He never lost hope and whenever his condition allowed he was discussing science with his group and guests until the very end.

All treatments had been tried, but unfortunately, he entered hospice care at the end of July 2019 and finally passed away quietly while being watched by his wife Susan. We can't believe that Chuck, who was so lively and active, disappeared. B.S.M., a former graduate student from Chuck's group, recalled that many graduate students used to say that Chuck would outlive most of us. Not by just a couple of years, but by a decade at least. Now, Chuck has left and we 


\section{eJSSNT}

ALC '19 Conference

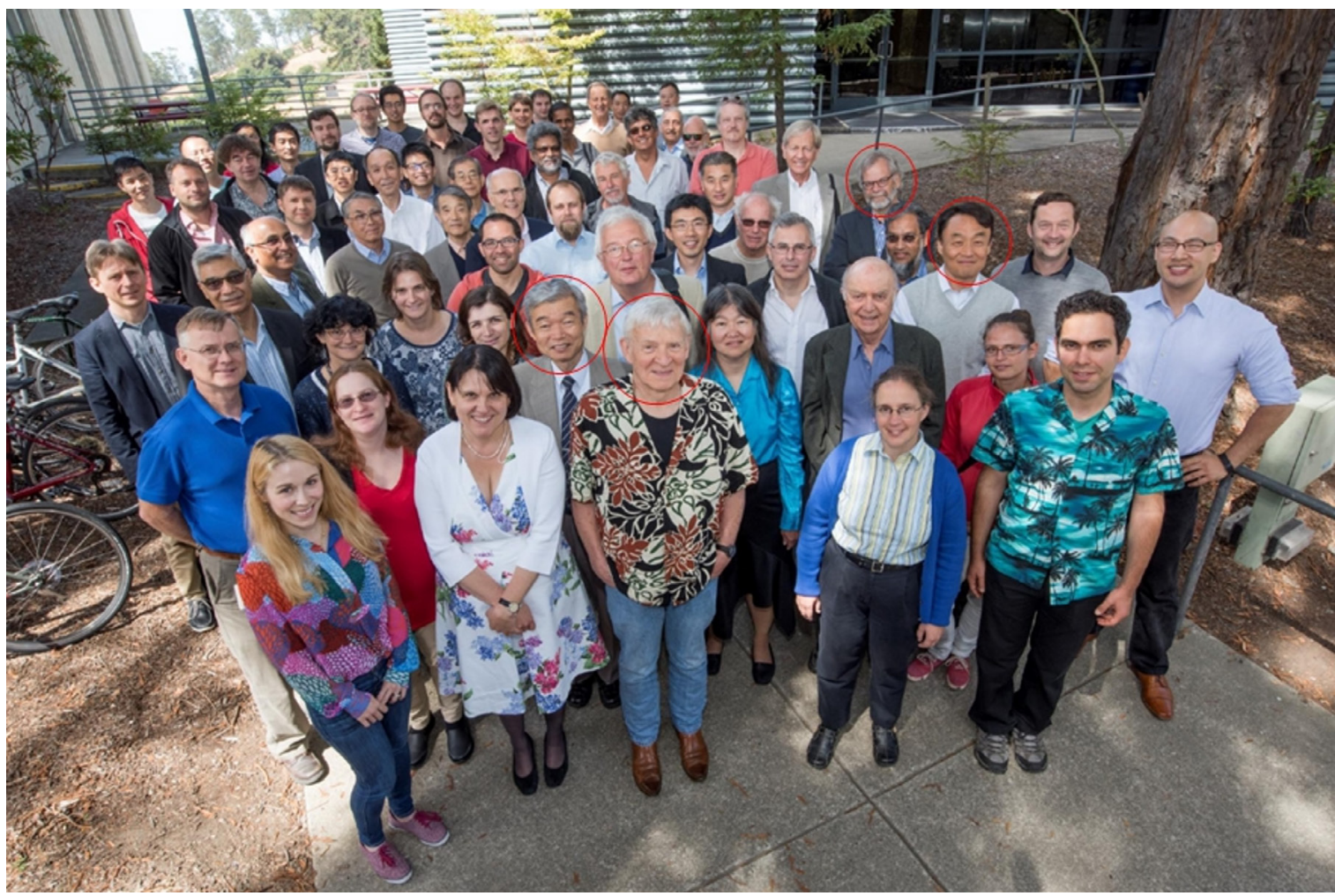

Figure 6: Group photo at Chuck's 75th birthday meeting. People surrounded by red circles are Chuck, H.D., B.S.M., and C.M.S. in the order of red circle size.

would like to pray with all of the readers of this article, giving thanks for his many years of great academic and social contributions, and his support for many researchers around the world.

\section{Note}

This memorial article is a summary of the memorial session for Chuck given by these authors conducted in at the 12th International Symposium on Atomic Level Characterizations for New Materials and Devices '19 (ALC '19), in conjunction with the 22nd International Conference on Secondary Ion Mass Spectrometry (SIMS-22), Miyako Messe, Kyoto, Japan, 20-25 October, 2019.

\section{References}

[1] S. Kono, C. S. Fadley, N. F. T. Hall, and Z. Hussain, Phys. Rev. Lett. 41, 117 (1978).

[2] S. Thevuthasan, G. S. Herman, A. P. Kaduwela, R. S. Saiki, Y. J. Kim, W. Niemczura, M. Burger, and C. S. Fadley, Phys. Rev. Lett. 67, 469 (1991).

[3] B. Sinković and C. S. Fadley, Phys. Rev. B 31, 4665 (1985).

[4] A. Kay, E. Arenholz, S. Mun, J. García de Abajo, C. S. Fadley, R. Denecke, Z. Hussain, and M. A. Van Hove, Science 281, 679 (1998).
[5] S.-H. Yang, B. S. Mun, A. W. Kay, S.-K. Kim, J. B. Kortright, J. H. Underwood, Z. Hussain, and C. S. Fadley, Surf. Sci. 461, L557 (2000).

[6] C. S. Fadley, Nucl. Instrum. Methods Phys. Res. A 547, 24 (2005).

[7] Web sites of JSPS Grant-in-Aid for Scientific Research on Innovative Areas "3D Active-Site Science";

http://www.en.3d-activesite.jp (in English), https://kaken.nii.ac.jp/ja/grant/KAKENHI-AREA-2604 (in Japanese).

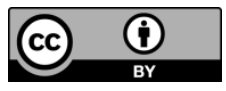

All articles published on e-J. Surf. Sci. Nanotechnol. are licensed under the Creative Commons Attribution 4.0 International (CC BY 4.0). You are free to copy and redistribute articles in any medium or format and also free to remix, transform, and build upon articles for any purpose (including a commercial use) as long as you give appropriate credit to the original source and provide a link to the Creative Commons (CC) license. If you modify the material, you must indicate changes in a proper way.

Published by The Japan Society of Vacuum and Surface Science 